\title{
Awareness of Colorectal Cancer and Associated Factors Among Adult Patients in Jimma, South- West Ethiopia.
}

Abdulmenan Hamza

Jimma University

Zeleke Argaw

Addis Ababa University, Ethiopia

Debela Gela ( $\nabla$ debegela@gmail.com )

Addis Ababa University, Ethiopia

\section{Research Article}

Keywords: Awareness, Colorectal cancer, Symptom, Risk factor, Patients, Jimma, Ethiopia.

Posted Date: December 2nd, 2020

DOI: https://doi.org/10.21203/rs.3.rs-111807/v1

License: (c) (i) This work is licensed under a Creative Commons Attribution 4.0 International License.

Read Full License 


\section{Awareness of Colorectal Cancer and Associated Factors among Adult Patients in Jimma, South-West Ethiopia.}

\section{Authors:}

1) Mr. Abdulmenan Hamza, BSc N, MSc

Lecturer

School of Nursing and Midwifery

Institute of Health

Jimma University

P.O. Box: 378, Jimma, Ethiopia

Telephone: +251943890230

E-mail: abduonco@gmail.com

2) Mr. Zeleke Argaw, BScN, MSc

Assistant Professor

School of Nursing \& Midwifery

College of Health Science

Addis Ababa University

P.O. Box: 4412, Addis Ababa, Ethiopia

Telephone: +251913179679

E-mail: zelekeargawm@yahoo.com

3) Mr. Debela Gela, *BSc N, MSc

Assistant Professor

School of Nursing \& Midwifery

College of Health Science

Addis Ababa University

P.O. Box: 4412, Addis Ababa, Ethiopia

Telephone: +251913179679

E-mail: debegela@gmail.com

*Corresponding author

Short Title: Adult Patients Awareness of Colorectal Cancer 


\section{Abstract}

Background: Colorectal cancer (CRC) is the first commonest diagnosed cancer in men and the fourth commonest in women in Ethiopia. The most significant factors that may increase the risk of having CRC were modifiable. However, little is known about the awareness of CRC and associated factors among adult patients in study area. Therefore, the study aimed to assess the awareness of CRC and associated factors among adult patients in Jimma, South-West Ethiopia, 2020.

Methods: The institution-based quantitative cross-sectional study design was conducted among 422 patients from March 8 to April 30, 2020. The study participants were recruited by a systematic random sampling method and data was collected semi-structured intervieweradministered questionnaires. Descriptive, bivariate, and multivariate logistic regression was implemented. The statistical level of significance was stated at $p$-value $<0.05$.

Result: A $100 \%$ response rate in this study was recorded. More than half (57.6\%) of the study participants had low awareness of colorectal cancer. Smoking (78.2\%) and bloody stool (49.3\%) were the most known risk factors and symptoms. There is a significant association between awareness of colorectal cancer with gender, residency, monthly income, level of education, information sources, and heard about CRC.

Conclusion: Overall awareness of patients towards CRC was inadequate. Participants with high levels of education and females had better awareness, however; the overall awareness of them was insufficient. Therefore, there is a need for awareness campaigns and health education for promoting colorectal cancer awareness.

Keywords: Awareness, Colorectal cancer, Symptom, Risk factor, Patients, Jimma, Ethiopia. 


\section{Introduction}

Cancer is an important global health problem in a developed and developing country that it is the most important cause of morbidity and mortality [1-3]. Furthermore, it affects the social and economic status of the population in the world [4]. It is expected to have grown to 18.1 million new cases and 9.6 million of the population died globally [2,5]. Cancer is proposed that an expected more than 20 million individuals will be identified, and around 13 million will be die in the year 2030 [6]. From this, the most commonly diagnosed cancers worldwide are colorectal cancer, lung, and breast cancers [7-9]. Cancer in sub-Saharan Africa (SSA) is on the rise caused by rapid population growth, higher life expectancy, and the adoption of unhealthy lifestyles, and a lack of awareness about cancer $[4,10,11]$.

Colorectal cancer (CRC) is the third commonest confirmed cancer in males and the second commonest in females in the world. It has grown to 1.8 million cases $(10.2 \%)$ with the biggest figure of deaths $(881000,9.2 \%)$ in the globe [5,12]. Majority of CRC is classified as adenocarcinoma, which mostly begins as a benign tumor, and changed to cancerous, and that may attack normal tissue, which spreads into the distant organ [13-17]. An elderly person, sex, prior colon disease (IBD), DM-2, a person with a family history of the CRC and polyp may have a greater, the incidence of CRC [18-23] which is collectively known as non-modifiable risk factors of CRC [3]. It becomes the highest frequent risk factor of CRC in Kuwait [24]. However, modifiable factors such as lack of physical activity, smoking, alcohol drinking, obesity, low fiber diet, high red meat, and low fruit and vegetable intake in the diet are the most important known factor [3,25-27]. It may increase the risk of having CRC by stimulating a multiplication of cancerous cell $[15,28]$. Modifiable factors were prevented by increasing awareness of the population about their life experience (lifestyle)[20,21,29-31] For instance, the risk of CRC is reduced by $40 \%$ with the practice of regular physical activity $(32,33)$ Similarly, CRC was the second commonest cancer in Malaysia; however, 18\% of CRC could be reduced by increasing public awareness with the application of regular physical activity, decrease body weight and stop alcohol intake[34] while CRC may present with warning symptoms such as bloody stool, unexplained weight loss, change in bowel habit, anemia, lower abdominal lump, rectal bleeding, and chronic abdominal pain [14,35-37].

In Sub-Saharan Africa, CRC is the commonest cancer that confirmed cases for 5.6\% in males and $3.7 \%$ in females. In Eritrea, it becomes higher among males than females to lack awareness 
about CRC risk factors and symptoms among the population [10,38]. Therefore, increasing the awareness of the general population about CRC may lead to a decrease the prevalence of the disease and rising willingness to involve in cancer screening [39,40]. This is important to early diagnosis, and treatment which may increase the survival rate [41,42] CRC is the third most common cancer in Ethiopia [6]. It becomes prevalent to account (12.2\%) in males and (4.4\%) in females [43]. The organization of healthy in Ethiopia mostly focused on the switch of communicable disease and, there is insufficient screening center, treatment facilities, and, unwell organized referral [6]. Therefore, non-communicable disease (NCD) like colorectal cancer is increasing rapidly [6]. So that today CRC in Ethiopia, become the first highest in men (19\%), and fourth-highest for women (5\%) [44]. Therefore, increasing awareness of colorectal cancer among the population has an unlimited influence on the prevention of disease, early diagnosis, and treatments and termination of disease prevalence.

The study conducted in the different country showed that the awareness score of the Bahraini population reaches to $(56 \%)$, among this $(63 \%)$ of the score was taken by participants who have higher education but it was still low score[18] while in Malaysia participants who had awareness about CRC symptoms (91.9\%) and risk factors (53.6\%) [45] Similar study done in Jordan indicate that the awareness of CRC among the population was low, however, females and participants who learn health-linked education had high awareness [46] Gender, age, marital status, educational level, income, family history of CRC, heard about CRC, and source of information were the most predictors of awareness of CRC [24,47,48]. Females, age above 50 years and higher income participants had high awareness which is significantly associated with awareness of CRC [18,31,49,50]. However, there is a limitation of study which assessed the awareness of CRC and its associated factors among adult patients in Ethiopia. Similarly, there is a potential gap considered in the current study area. Though, increasing the awareness of people about lifestyle modification, predictors' identification, and recognizing warning signs and symptoms may important to reduce colorectal cancer morbidity and mortality. In addition to this, it is an indispensable primary phase to ensure their health well-being and experience of a healthy lifestyle to decline CRC prevalence. The finding of this research will be used as a baseline tool for researchers, policymakers to design policies, plans, and intervention programs for down hilling prevalence of $\mathrm{CRC}$ in the public. Ultimately, this study will help the patients in reducing increased health care costs, reduce hospital stay in the case of $\mathrm{CRC}$, and improves the quality of 
life. Generally, awareness of colorectal cancer-related factors and warning symptom is crucial among the population in Ethiopia. Therefore, this study aims to assess the awareness of colorectal cancer and associated factors among adult patients in Jimma, South-West, Ethiopia.

\section{Methods and Materials}

\section{Study Design, Area, and Population}

The institutional-based quantitative cross-sectional study design was employed from March to April 2020 at Jimma University Medical Center (JUMC) placed in Jimma town, which is located 354 kilometers from the capital Addis Ababa within the southwest of Ethiopia. It is one of the largest institutions giving service for cancer treatment and care in Ethiopia. It has a total bed capacity of around 675 with nearly 1900 hospital staff. All adult (18 years and above) volunteer adult patients who had been attending adult medical and surgical outpatient clinic of JUMC during the data collection period were included, except patients who had a history of CRC, mentally ill, chronically ill, critically sick, visual and hearing disorder, and unable to speak during the data collection period. The net sample of 422 was employed using a systematic random sampling technique. This sample size yielded with considering marginal error $(d)=5 \%$, and $95 \%$ confidence level, $\alpha=0.05$. The sampling frame for the systematic sampling technique was the HMIS case registry book. For all cases, $\mathrm{K}$ was 35 and between 1 and 35 . The first comer patient took as a primary sample then every 35 intervals until getting the 14 samples with each day at the selected adult outpatient clinic.

\section{Data Collection Tools and Procedures}

Data was collected using an interviewer-administered structured questionnaire. The data instrument included two parts. Part one: as socio-demographic data including information related factors. Part two comprised Cancer Awareness Measure questions (CAM) which adapted from the University College London and Cancer Research in the UK in 2008 and were intended to examine the general public's awareness of CRC in the United Kingdom with some modifications after serious literature review [51] and using question with "Yes or No" answers, where "Yes" indicated for the exact response which scores 1. A participant got an excellent mark of twenty out of twenty when the whole questions were responded to exactly. An accumulative mark of respondent's on awareness of CRC ranging from (0-20) which was acquired by the accumulation of exact response to the 20 -item questionnaire. A total mark of 15 or more ( $\geq 75 \%)$ was referred to as the participants were attaining high awareness; whereas participants who score 
less than $15(<75 \%)$ were attaining low awareness [19,41,48,51,52]. For this study, the instruments on awareness of colorectal cancer were interpreted to Amharic version, then local language Afan Oromo via a back to back translation approach. The instrument was certified before being used in this work as defined in the section. The certification result revealed that there was 96\% consent between the Amharic, Afan Oromo, and English instruments. To assure the quality of data, the following measures were taken. The questionnaire was adopted from the CAM questionnaire. Its Cronbach's alpha coefficient was 0.84 and the content validity index was 0.7 (Nasaif and Al Qallaf, 2018). A Pre-test was conducted on 42 adult patients in Shenen Gibe General Hospital in Jimma Zone one week before the actual data collection and the questionnaire had been checked for its clarity, understandability, and simplicity. After the pre-test, the questionnaires were reviewed and reformatted based on the inputs and comments generated by seniors. After this, the internal consistency (Cronbach's- $\alpha$ ) in this study was 0.90 which can be considered adequate. Both the principal investigator and recruited supervisors had been responsible for supportive supervision on the spot and on reviewing all filled questionnaires on daily basis. Data collectors and supervisors were enrolled in training for two days on the objective of the study, instrument, and data collection procedures by the principal investigator. The supervisors were checking the questionnaire for completeness and closely supervise data collectors and presented to the principal investigators. Moreover, the collected data was coded, cleaned, and explored by the principal investigator before analysis.

\section{Data Entry, Analysis, and Presentation}

The assembled data was checked its completeness and consistencies before data entry. Answers in each question were labeled for easiness of data entrance. The coded data were entered into Epi data version 4.6.0 and exported to SPSS version, 25 was used for data analysis. Descriptive analysis, bivariate, and multivariate logistic regression models were carried out to describe and identify factors that affect awareness of CRC. The AOR was used to determine the strength of association and statistically significance at $95 \%$ confidence interval (CI). Then significant factors with p-value < 0.25; CI- $95 \%$ in bivariate analysis were entered into multivariate logistic regression models to control the effect of confounding factors, and the statistical test of association was considered significant at a p-value of $<0.05$. Then the result of the study was presented in figures and tables. 


\section{Ethical Consideration}

An ethical clearance letter was gained from the institutional Review Board (IRB) of Addis Ababa University College of Health Science (Protocol No. IRB/059/20/SNM). A permission letter was obtained from Addis Ababa University, College of Health Sciences School of Nursing and Midwifery to the administrator of the study site. A letter of permission was secured from the administrative bodies of the hospitals. All of the study participants were informed about the purpose of the study, written informed consent was obtained and they are informed that participating in this study was fully voluntary. Besides, the confidentiality of the information was assured. The study was conducted following the Declaration of Helsinki. The IRB office in Addis Ababa University, College of Health Sciences School of Nursing and Midwifery approved the consent process.

\section{Results}

\section{Socio-demographic characteristics of participants}

A total of 422 with response rate (100\%) patients participated in this study. Table 1 shows almost half $(\mathrm{n}=212,50.2 \%)$ of participants were male, with a mean age of $47.30 \pm 17.81$ (Range $=20-83)$ years, and $(n=229,54.3 \%)$ of the participants were between the ages group of 20 49 years. More than half $(\mathrm{n}=263,62.3 \%)$ of the participants were married and $(\mathrm{n}=212,50.2 \%)$ were followers of the Muslim religion. Most $(\mathrm{n}=240,56.9 \%)$ of the participants live in rural area. As for the educational level $(\mathrm{n}=98,23.2 \%)$ of participants attended elementary $(1-8)$ school while $(\mathrm{n}=74,17.5 \%)$ attended college and above. About more than half of $(\mathrm{n}=240$, $56.9 \%)$ of participants earn monthly income lower than 3000 Ethiopian birrs, and $(n=248$, $58.8 \%)$ of participants heard about colorectal cancer. Only $(\mathrm{n}=17,4 \%)$ of participants had a family history of CRC and more than half $(237,56.2 \%)$ of the participants responded that CRC is

a preventable disease (Table 1). More than one third $(n=74,29.8 \%)$ of the participants had received information regarding $\mathrm{CRC}$ from mass media followed by social media $(\mathrm{n}=55,22.2 \%)$ (Figure 1). 
Table 1: Socio demographic characteristics of respondents in Jimma University Medical Center, Jimma, South-West Ethiopia, $2020(\mathrm{n}=422)$.

\begin{tabular}{|c|c|c|c|}
\hline Characteristics & & Frequency(n) & Percent (\%) \\
\hline \multicolumn{4}{|l|}{ Age in year } \\
\hline & $20-29$ & 88 & 20.9 \\
\hline$($ Mean $=47.3)$ & $30-39$ & 85 & 20.1 \\
\hline \multirow{2}{*}{$(\mathrm{SD}=17.81)$} & $40-49$ & 56 & 13.3 \\
\hline & $\geq 50$ & 193 & 45.7 \\
\hline \multicolumn{4}{|l|}{ Sex } \\
\hline & Male & 212 & 50.2 \\
\hline & Female & 210 & 49.8 \\
\hline \multicolumn{4}{|l|}{ Marital Status } \\
\hline & Single & 113 & 26.8 \\
\hline & Married & 263 & 62.3 \\
\hline & Widowed & 35 & 8.5 \\
\hline & Divorced & 11 & 2.6 \\
\hline \multicolumn{4}{|l|}{ Religion } \\
\hline & Muslim & 212 & 50.2 \\
\hline & Orthodox & 131 & 31 \\
\hline & Protestant & 75 & 17.8 \\
\hline & Others & 4 & 0.9 \\
\hline \multicolumn{4}{|l|}{ Residency } \\
\hline & Urban & 236 & 55.9 \\
\hline & Rural & 186 & 44.1 \\
\hline \multicolumn{4}{|l|}{ Monthly Income } \\
\hline & 3000 ETB and Above & 182 & 56.9 \\
\hline & Below 3000 ETB & 240 & 43.1 \\
\hline \multicolumn{4}{|l|}{ Heard about CRC } \\
\hline & Yes & 248 & 58.8 \\
\hline & No & 174 & 41.2 \\
\hline \multicolumn{4}{|c|}{ Family history of CRC } \\
\hline & Yes & 237 & 56.2 \\
\hline & No & 185 & 43.8 \\
\hline
\end{tabular}

ETB; Ethiopian Birr 
Figure 1: Sources of information about CRC among patients JUMC, Jimma, South-West Ethiopia, $2020(\mathrm{n}=422)$.

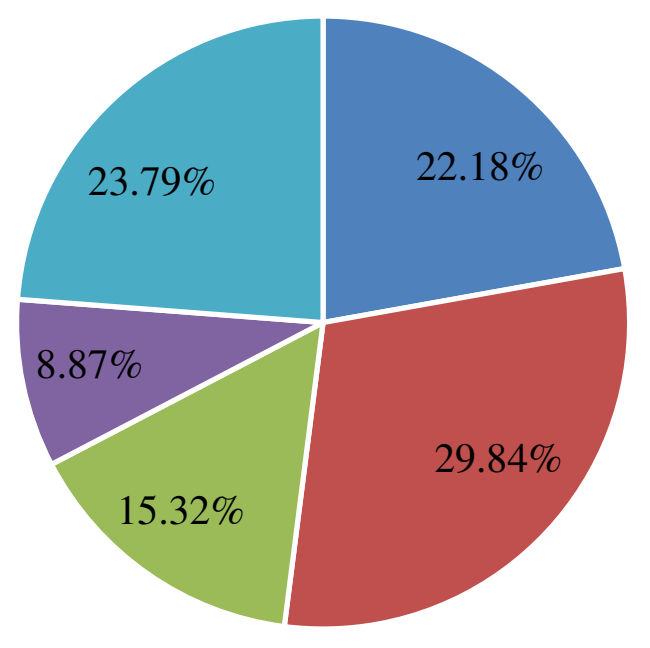

\section{Information Aids}

- Social media

- Mass media

- Hospital

- Pear group

- Others(family, Curriculum etc.)

\section{Awareness of participants toward Colorectal Cancer}

The study finding indicates that more than three fourth $(n=330,78.2 \%)$ of participants thought that the commonest modifiable agent that was a risk of CRC were smoking followed by alcohol consumption $(n=327,77.5 \%)$ however, the least factors that were recognized by participants were aging $(n=150,35.5 \%)$ and DM-2 $(n=137,32.5 \%)$. Similarly, $(n=248,58.8 \%)$ of participants known that lack of vegetables and fruits intake in the diet may increase the risk of CRC. Two hundred eight $(n=208,49.3 \%)$ of participants understood that blood in stool was the commonest warning symptom of CRC followed by chronic abdominal pain ( $\mathrm{n}=203,48.1 \%)$, and change in bowel habit $(n=199,47.2 \%)$ and more than one third $(n=164,38.9 \%)$ of participants said that anemia is the warning symptoms of CRC. However, the least symptom of CRC that was understood by $(n=143,33.9 \%)$ of patients was a lump in the lower abdomen (Table2). The overall level of awareness showed that the majority $(n=243,57.6 \%)$ of patients attending Jimma University Medical Center had low awareness, and $(n=179,42.4 \%)$ of patients had high awareness about colorectal cancer (Figure 2). 
Figure 2: Overall level of awareness of patients attending JUMC, Jimma, South-West Ethiopia, $2020(n=422)$.

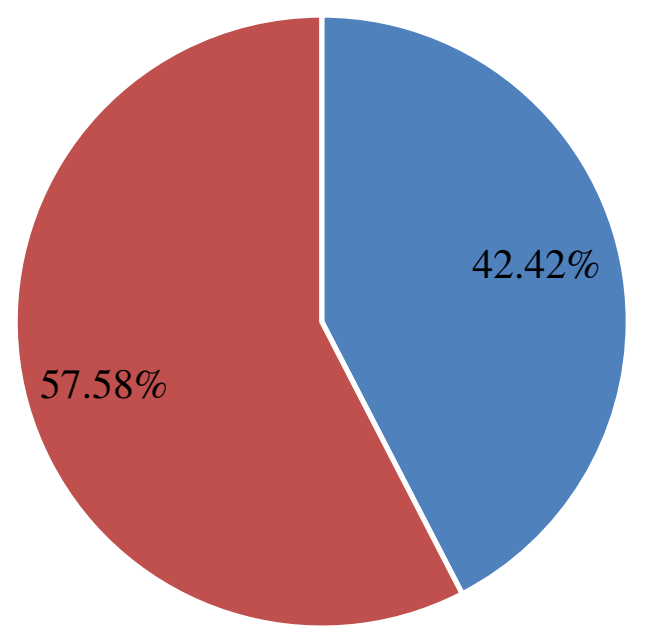

\section{Level of Awareness}

- High awareness

- Low awareness

\section{Factors associated with awareness of colorectal cancer}

The finding of this study revealed that gender, monthly income, residency, level of education, heard about CRC, information sources, and family history of $\mathrm{CRC}$ are identified as factors associated with awareness toward colorectal cancer among patients. The study participants who were females are almost 1.9 times more likely to have high awareness towards colorectal cancer with adjusted odds ratio $[\mathrm{AOR}=1.86 ; 95 \% \mathrm{CI}:(1.26,2.75)]$ as compared to male. Patients who are living in urban areas were 55\% less likely had low awareness of colorectal cancer with [AOR $=0.45 ; 95 \% \mathrm{CI}:(0.30,0.67)]$ than those participants living in a rural area. Moreover, patients who earn a monthly income of 3000ETB and above were 4.7 times more likely had high awareness of colorectal cancer with $[\mathrm{AOR}=4.72$; 95\% CI: $(3.11,7.15)]$ with compared to the patients who earn below 3000ETB.

Similarly, study participants who cannot read and write, can read and write, and learn elementary school (1-8) were 2.8 times, 2.7 times and 2.1times more likely had low awareness towards colorectal cancer with $[\mathrm{AOR}=2.83 ; 95 \% \mathrm{CI}:(1.49,5.37)]$, [2.77; 95\%CI: $(1.43,5.34)]$ and $[2.12$; 95\%CI: $(1.15,3.93)]$ respectively as compared to those patients educational level of collage and 
above. Besides, patients who heard about colorectal cancer were 4.5 times [AOR=4.48; 95\% CI: $(2.90,6.93)]$ more likely had high awareness to colorectal cancer compared to never heard about colorectal cancer. Similarly, patients who get information through social media about colorectal cancer were 2.5 times $[\mathrm{AOR}=2.51 ; 95 \% \mathrm{CI}:(1.18,5.37)]$ more likely had high awareness of colorectal cancer than those who get information through other sources. Finally, patients who have a family history of colorectal cancer were 3.2 times [AOR=3.27; 95\% CI: $(1.45,7.36)$ ] more likely had high awareness of colorectal cancer compared to who have not a family history of colorectal cancer (Table 2).

Table 2: Predictors of awareness of colorectal cancer among patients attending in JUMC, Jimma, South-West Ethiopia, $2020(n=422)$.

\begin{tabular}{|c|c|c|c|c|c|c|}
\hline \multirow[t]{2}{*}{ Variable } & & \multicolumn{2}{|c|}{ Level of Awareness } & \multirow[b]{2}{*}{ COR $(95 \% \mathrm{CI}$} & \multirow[b]{2}{*}{$\operatorname{AOR}(95 \% \mathrm{CI})$} & \multirow[b]{2}{*}{$p$-value } \\
\hline & & $\begin{array}{l}\text { High } \\
\text { n (\%) }\end{array}$ & $\begin{array}{l}\text { Low } \\
\text { n }(\%)\end{array}$ & & & \\
\hline \multirow[t]{2}{*}{ Gender } & Male & $74(41.3)$ & $138(56.8)$ & $0.53(0.36,0.79) *$ & $1.86(1.26,2.75) * *$ & 0.002 \\
\hline & Female & $105(58.7)$ & $105(43.2)$ & 1 & 1 & \\
\hline \multirow[t]{2}{*}{ Residency } & Urban & $97(54.2)$ & $85(35)$ & $2.19(1.48,3.26) *$ & $0.45(0.30,0.67)^{* *}$ & 0.000 \\
\hline & Rural & $82(45.8)$ & $158(65)$ & 1 & 1 & \\
\hline Monthly & Below 3000ETB & $64(35.8)$ & $176(72.4)$ & $0.21(0.14,0.32) *$ & $4.72(3.11,7.15) * *$ & 0.000 \\
\hline Income & Above 3000ETB & $115(64.2)$ & $67(27.6)$ & 1 & 1 & \\
\hline \multirow[t]{5}{*}{ Education } & Can't read \&write & $30(16.8)$ & $58(23.9)$ & $0.35(0.18,0.66) *$ & $2.83(1.49,5.37)^{* *}$ & 0.001 \\
\hline & Can read \&write & $27(15.1)$ & $51(21)$ & $0.36(0.18,0.69) *$ & $2.77(1.43,5.34)^{* *}$ & 0.002 \\
\hline & Elementary 1-8 & $40(22.3)$ & $58(23.9)$ & $0.47(0.25,0.86) *$ & $2.12(1.15,3.93)^{* *}$ & 0.016 \\
\hline & High school & $38(21.2)$ & $46(18.9)$ & $056(0.29,1.06)$ & $1.77(0.94,3.34)$ & \\
\hline & Collage \& Above & $44(24.6)$ & $30(12.3)$ & 1 & 1 & \\
\hline Heard & No & $39(21.8)$ & $135(55.6)$ & $0.22(0.11,0.34) *$ & $4.48(2.90,6.93)^{* *}$ & 0.000 \\
\hline About CRC & Yes & $140(78.2)$ & $108(44.4)$ & 1 & 1 & \\
\hline Information & Social media & $24(17.1)$ & $31(28.7)$ & $0.39(0.18,0.84) *$ & $2.51(1.18,5.37)^{* *}$ & 0.017 \\
\hline \multirow[t]{4}{*}{ Sources } & Mass media & $46(32.9)$ & $28(25.9)$ & $0.84(0.41,1.77)$ & $1.18(0.58,2.42)$ & \\
\hline & Hospital & $21(15.0)$ & $17(15.7)$ & $0.63(0.27,1.46)$ & $1.57(0.68,3.64)$ & \\
\hline & Pear group & $10(7.1)$ & $12(11.1)$ & $042(0.15,1.15)$ & $2.34(0.86,6.34)$ & \\
\hline & Others & $39(27.9)$ & $20(18.5)$ & 1 & 1 & \\
\hline
\end{tabular}

$* \mathrm{p}<0.25$, CI; Confidence Interval, COD; crude odds ratio, AOD; adjusted odds ratio, ** Statistically significant at p-value $<0.05$ in adjusted odds ratio, ETB; Ethiopian birr 


\section{Discussion}

This is the first study investigating the awareness of CRC and its associated factors among the population in Ethiopia. Increasing awareness toward CRC is a cornerstone for better prevention, early detection, and care of patients with advanced colorectal cancer and cancer-related complications. Unlike this, it increases the prevalence of advanced disease and CRC-related mortality. Hence, this study assesses awareness of CRC and its associated factors among patients The overall score of awareness of patients attending Jimma university medical center was $42.40 \%$. This indicates more than half of participants have low awareness about colorectal cancer which will contribute to unhealthy lifestyle practice, which leads to increases in the incidence of CRC. This finding is lower than the finding of studies conducted in the Kingdom of Bahrain which is $56 \%$ [18]. This might be due to the difference in socio-economic status and organizational policies and access to the information-related to $\mathrm{CRC}$, and its risk factors. The result of this study is also lower than the finding of studies conducted in Pakistan [53] which is 66.6\%. This discrepancy might be due to differences in the study population in which the Pakistan study included only young university students and might be getting awareness through the educational curriculum. Conversely, this finding is also lower than the study done in Malaysia which is $91.9 \%$ and $53.6 \%$ of symptoms and risk factors of CRC respectively. ${ }^{45}$ This higher score difference might be explained by the fact that information access in Malaysia encompassed in the educational curriculum from nursery through higher secondary education and telemedicine also giving service and application in urban area [54,55].

In general, the finding of the current result about awareness of CRC regarding risk factors and symptoms become inadequate (low). This result is consistent with a study done in Jordan [46] which is awareness of colorectal cancer symptoms and risk factors among participants were $(32.8 \%)$ and $(16.5 \%)$ respectively.

The current study showed that participants who are female had a high awareness about CRC which is consistent with the finding of the study conducted in the Gaza strip [56] and, Jordan [46]. This discrepancy between genders might be due to females might had more exposure to cancer-related health education or information connected to their reproductive health service encounter compared to their male counterparts and also might be due to females give attention to their health and have the desired discussion however CRC is still frequent in men. This result is supported by the different studies done around the globe [18,49,50,56]. 
The commonest risk factors that aware by participants were smoking cigarettes $78.2 \%$ and alcohol consumption (77.5\%). This result is almost in line with the study done in Gaza strip [56] which is (76.7\%). Conversely, this finding is higher than the study in Kuwait which is almost each to (70\%) [4]. This might be due to differences in governmental health policy and accessibility of public health education about the effects and consequences of smoking and alcohol consumption. Conversely, the symptom that was least aware by participants was DM-2 (32.5\%). However, DM-2 is strong, significant associated with awareness of CRC $(\mathrm{P}=0.000, \mathrm{P}$ $<0.05)$. This is almost consistent with the studies conducted in Kuwait [24] which are 31\%. The result shows low awareness of participants about DM-2 as a risk of CRC. This would underline the need for public awareness about diabetes from the time when it is a significant risk factor of CRC. This result is supported by the study done in Roman [57]. It also increases late diagnosis and tendency to poor outcome after treatment [58].

This study reported that awareness of participant's that lack of physical exercise is risk factors for CRC were $56.6 \%$. This result shows higher than the study conducted in Kuwait [24] which is $50 \%$. This might be due to awareness of physical activity increase due to governmental action that starting mass sport that reduces chronic illness. Conversely, the study result is lower than the study done in the Kingdom of Saudi Arabia [47] which is 66\%. This might be due to governmental action on practicing physical activity was limited to some urban area of the country. Besides, this discrepancy might be due to individual behaviors like using their own automobile, being busy, standards of lifestyle, and lack of time.

This study showed that almost half (49.3\%) of participants were aware of blood in stool, and change in bowel habits (47.2\%). This finding is higher than the study conducted in Madinah, Saudi Arabia [49] which is $(45.9 \%)$ and (34.8\%) respectively. This difference might be due to knowing the anatomical position that symptom experienced and peoples might be considering chronic hemorrhoid leads to CRC as the same symptom. Conversely, the result was lower than the study done in Kuwait [24] which is (55\%) and (56\%) respectively. The possible justification might be due to the level of education difference among study participants that might be contributed to this result. In which $73 \%$ of participants join higher education in Kuwaiti study.

Gender, residency, level of education, monthly income, heard about CRC, information sources, positive family history of CRC, were identified as factors that significantly associated with 
awareness of colorectal cancer among patients in this study. Those patients who are living in urban areas were $54.5 \%$ less likely to have low awareness of colorectal cancer than those participants living in a rural area. This study finding is consistent with the study done in Malaysia [59]. The probable reason for this might be due to patients living in an urban area might have frequently get information through mass media (Television, Radio), social media, and they developed better awareness in using these types of information sources. Patients who cannot read and write, can read and write, and learn elementary school were almost three times, three times and two times more likely had low awareness towards colorectal cancer respectively as compared to those patients with higher educational levels. This result is consistent with the study done in Bahrain [18]. The possible justification for this might be patients with joined college and university might get information through curriculum and work experience about colorectal cancer, this might increase awareness of colorectal cancer toward risk factors and symptoms.

Those patients who earn a monthly income of 3000ETB and above were four times more likely had high awareness of colorectal cancer compared to those patients who earn below 3000ETB. This indicates income is significantly associated with awareness of the patients as $(\mathrm{P}=0.000, \mathrm{P}$ $<0.05)$. This result is supported by the study done in Malaysia [45]. This might be related to those patients who earn better monthly income were more satisfied by their income to initiated in gathering information with different information systems like join in different social media like the internet at home, Facebook, YouTube, and telegrams and using mass media like television and radio.

Patients who heard about colorectal cancer were almost five times more likely to have high awareness of colorectal cancer compared to never hear about colorectal cancer. Similarly hearing about CRC is strong significantly associated with awareness of colorectal cancer $(\mathrm{p}=0.00, \mathrm{p}<$ 0.05, 95\% CI). This finding is consistent with the study done in Madinah, Saudi Arabia [45]. The possible justification for this might be participants live in an urban area that may have access to health-related information or they may live nearby cancer awareness campaigns. This might be enhancing awareness about the important disease and increase personal disease preventive practice. Obtaining information through social media was two times more likely to have high awareness of colorectal cancer than those who get information through other sources. Sources of information via social media is statistically significant at $(\mathrm{P}=0.017, \mathrm{P}<0.05)$. This result is 
consistent with the study conducted in Madinah, KSA [48] which is the most source of information that the participants used for increasing awareness about CRC followed by relatives $(13 \%)$ curriculum $(11 \%)$, and television $(6 \%)$. The possible justification might be information that was required by participants was available anytime and anywhere if the internet was available. It might be also information through social media was not need a fixed period or time for obtaining information about CRC than others. In general, the information about CRC was significantly associated with awareness of colorectal cancer. This result is also supported by a study done in Saudi Arabia [47].

\section{Conclusion}

In conclusion, almost two-thirds of the study participants had low awareness about colorectal cancer. Similarly, the awareness of signs and symptoms of CRC among participants had very low compared to that of risk factors. Participants with high levels of education, high income, age more than 50 years, and females had better awareness of CRC, however, the overall situation is unhappy. Gender, residency, level of education, monthly income, heard about CRC, and sources of information were significantly associated with awareness of CRC. Maximizing awareness about CRC and associated factors play an important role in preventing and reducing the incidence of CRC. Therefore, the study finding recommended that initiating structured awareness campaigns and devoting an awareness month for this disease can maximize awareness about CRC. In addition to this, promoting these activities on mass media and social media will help address information to a wider range of audiences.

\section{Limitation of the Study}

The limitation of similar studies conducted in Ethiopia makes the comparison and discussion challenging. Finally, this study was the cross-sectional nature of the study design does not confirm the definitive cause and effect relationship between the variables.

\section{Abbreviations}

AOR: Adjusted Odds Ratio, CAM: Cancer Awareness Measure, CRC: Colorectal cancer, CI:

Confidence Interval, DM-2: Type two Diabetes Mellitus, HMIS: Health Management Information System, IBD: Inflammatory Bowel Disease, JUMC: Jumma University Medical Center, KSA: Kingdom of Saudi Arabia, NCD: Non-Communicable Disease. 


\section{Ethics approval and consent to participate}

This study was reviewed and approved by an Institutional Review Board of the College of Health Sciences, Addis Ababa University, Addis Ababa, Ethiopia (Protocol No: IRB/059/20/SNM). All participants provided written informed consent. The study was conducted in accordance with the Declaration of Helsinki.

\section{Consent for publication}

Not applicable

\section{Availability of data and materials}

The datasets used and/or analyzed during the current study are available from the author on reasonable request.

\section{Competing interests}

The authors declare that they have no competing interests. The author's acknowledged Addis Ababa University for this paper was uploaded to the Addis Ababa University repository as a thesis in June, 2020 [60].

\section{Funding and Support}

The cost of the study was covered by Addis Ababa University.

\section{Authors' contributions}

AH planned the study, involved in data collection, prepared the proposal, conducted data analysis, and prepared the manuscript. ZA contributed to the study conception and design, supervised the study, and data analysis. DG contributed to data analysis, supervised the study, and critically supervised the manuscript.

\section{Acknowledgment}

Our deepest gratitude goes to Addis Ababa University, School of Nursing, and Midwifery for financial support. We would like to extend our sincere gratitude to the data collectors, supervisors, and the study participants for being involved in the study. 


\section{References}

1. Niksic M, Rachet B, Duffy SW, Quaresma M, Møller H, Forbes LJ. Is cancer survival associated with cancer symptom awareness and barriers to seeking medical help in England? An ecological study. British journal of cancer. 2016;115(7):876.

2. Bray F, Ferlay J, Soerjomataram I, Siegel RL, Torre LA, Jemal A. Global cancer statistics 2018: GLOBOCAN estimates of incidence and mortality worldwide for 36 cancers in 185 countries. CA: a cancer journal for clinicians. 2018;68(6):394-424.

3. American Cancer Association. Cancer Facts \& Figures 2017 [Internet]. American Cancer Society Atlanta; 2017.

4. Harford JB. Barriers to overcome for effective cancer control in Africa. The Lancet Oncology. 2015;16(8):e385-e393.

5. WHO. International Agency for Research on Cancer Global cancer observatory. World Health Organization http://gco iarc fr Accessed. 2018;8.

6. Federal Ministry of Health; Ethiopia: National Cancer Control Plan 2016-2020 October 2015: Addis Ababa Ethiopia (https://www.iccp-portal.org/ sites/default/files/plans/NCCP\%20Ethiopia\%20Final\%20261015.pdf. Accessed 2020.

7. Torre LA, Bray F, Siegel RL, Ferlay J, Lortet-Tieulent J, Jemal A. Global cancer statistics, 2012. CA: a cancer journal for clinicians. 2015;65(2):87-108.

8. McGuire S. World cancer report 2014. Geneva, Switzerland: World Health Organization, international agency for research on cancer, WHO Press, 2015. Oxford University Press; 2016.

9. Woldu M, Legese D, Abamecha F, Berha A. The Prevalence of Cancer and its Associated Risk Factors among Patients Visiting Oncology Unit, Tikur Anbessa Specialized Hospital, Addis Ababa-Ethiopia. J Cancer Sci Ther. 2017;9:414-421.

10. McCormack V, Newton R. . Research priorities for social inequalities in cancer in subSaharan Africa. 150 cours Albert Thomas, 69372 Lyon Cedex 08, France@ International Agency for Research on Cancer, 2019 Distributed by WHO Press, World Health Organization, 20 Avenue Appia, 1211 Geneva 27, Switzerland. 2019:319.

11. May FP, Anandasabapathy S. Colon cancer in Africa: Primetime for screening? Gastrointestinal endoscopy. 2019;89(6):1238-1240. 
12. Safiri S, Sepanlou SG, Ikuta KS, et al. The global, regional, and national burden of colorectal cancer and its attributable risk factors in 195 countries and territories, 1990-2017: a systematic analysis for the Global Burden of Disease Study 2017. The Lancet Gastroenterology \& Hepatology. 2019;4(12):913-933.

13. Bower M, Waxman J. Lecture Notes: Oncology. John Wiley \& Sons; 2015.

14. Society AC. Global Cancer Facts \& Figures 3rd Edition. American Cancer Society. 2015;800:1-64.

15. Keum N, Giovannucci E. Global burden of colorectal cancer: Emerging trends, risk factors and prevention strategies. Nature Reviews Gastroenterology \& Hepatology. 2019:1-20.

16. Amini AQ, Samo KA, Memon AS. Colorectal cancer in younger population: our experience. J Pak Med Assoc. 2013;63(10):1275-1277.

17. Granados-Romero J, Valderrama-Treviño A, Contreras Flores E, et al. Colorectal cancer: a review. International Journal of Research in Medical Sciences. 2017;5:4667.

18. Nasaif HA, Al Qallaf SM. Knowledge of colorectal cancer symptoms and risk factors in the Kingdom of Bahrain: A cross-sectional study. Asian Pacific journal of cancer prevention: APJCP. 2018;19(8):2299.

19. Tfaily MA, Naamani D, Kassir A, et al. Awareness of Colorectal Cancer and Attitudes Towards Its Screening Guidelines in Lebanon. Annals of global health. 2019;85(1).

20. Wild CP. The global cancer burden: necessity is the mother of prevention. Nature Reviews Cancer. 2019;19(3):123.

21. Vuik FE, Nieuwenburg SA, Bardou M, et al. Increasing incidence of colorectal cancer in young adults in Europe over the last 25 years. Gut. 2019:gutjnl-2018-317592.

22. Alberts DS, Hess LM. Introduction to cancer prevention. Fundamentals of Cancer Prevention: Springer; 2019:1-16.

23. Jeon J, Du M, Schoen RE, et al. Determining risk of colorectal cancer and starting age of screening based on lifestyle, environmental, and genetic factors. Gastroenterology. 2018;154(8):2152-2164. e2119.

24. Saeed RS, Bakir YY, Alkhalifah KH, Ali LM. Knowledge and Awareness of Colorectal Cancer among General Public of Kuwait. Asian Pacific journal of cancer prevention: APJCP. 2018;19(9):2455. 
25. Katsidzira L, Gangaidzo IT, Makunike-Mutasa R, et al. A case-control study of risk factors for colorectal cancer in an African population. European Journal of Cancer Prevention. 2019;28(3):145-150.

26. Siegel RL, Torre LA, Soerjomataram I, et al. Global patterns and trends in colorectal cancer incidence in young adults. Gut. 2019;68(12):2179-2185.

27. Arnold M, Sierra MS, Laversanne M, Soerjomataram I, Jemal A, Bray F. Global patterns and trends in colorectal cancer incidence and mortality. Gut. 2017;66(4):683-691.

28. Favoriti P, Carbone G, Greco M, Pirozzi F, Pirozzi REM, Corcione F. Worldwide burden of colorectal cancer: a review. Updates in surgery. 2016;68(1):7-11.

29. Wardle J, Marlow LA. Public awareness of cancer screening. Cancer Prevention and Screening: Concepts, Principles and Controversies. 2018:57.

30. Zubaidi A, Alsubaie M, AlHumaid A, Shaik S, Al-Khayal K, AlObeed O. Public Awareness of Colorectal Cancer in Saudi Arabia: A Survey of 1070 Participants in Riyadh. Saudi journal of gastroenterology : official journal of the Saudi Gastroenterology Association. 2015;21:78-83.

31. Lubbad H, Almahallawi B, Samaan M, et al. Public Awareness and Barriers to Seeking Medical Advice for Colorectal Cancer in the Gaza Strip: A Cross-Sectional Study. 2019.

32. López PJT, Albero JS, Rodríguez-Montes JA. Primary and secondary prevention of colorectal cancer. Clinical Medicine Insights: Gastroenterology. 2014;7:CGast. S14039.

33. ALmutlaq B, Bokhari B, Alharbi H, Alzayed A, Abouhamda A. Assessment of Awareness Levels toward Colorectal Cancer Early Detection and Prevention in Saudi Arabia. Gastroenterol Hepatol Open Access. 2017;6(3):00195.

34. Naing C, Lai PK, Mak JW. Immediately modifiable risk factors attributable to colorectal cancer in Malaysia. BMC public health. 2017;17(1):637.

35. Dark GG. Oncology at a Glance. John Wiley \& Sons; 2013.

36. Thanikachalam K, Khan G. Colorectal cancer and nutrition. Nutrients. 2019;11(1):164.

37. Sanderson SC, Waller J, Jarvis MJ, Humphries SE, Wardle J. Awareness of lifestyle risk factors for cancer and heart disease among adults in the UK. Patient education and counseling. 2009;74(2):221-227.

38. Medhin LB, Achila OO, Abrham AT, et al. Incidence of colorectal cancer in Eritrea: Data from the National Health Laboratory, 2011-2017. PloS one. 2019;14(11). 
39. Al-Hajeili M, Abdulwassi HK, Alshadadi F, Alqurashi L, Idriss M, Halawani L. Assessing knowledge on preventive colorectal cancer screening in Saudi Arabia: A cross-sectional study. Journal of Family Medicine and Primary Care. 2019;8(10):3140.

40. Le Bonniec A, Mas S, Préau M, Cousson-Gélie F. Understanding barriers and facilitators to participation in colorectal cancer screening: A French qualitative study. Journal of Health Psychology. 2020:1359105320909883.

41. Bidouei F, Abdolhosseini S, Jafarzadeh N, et al. Knowledge and perception toward colorectal cancer screening in east of Iran. International journal of health policy and management. 2014;3(1):11.

42. Kolligs FT. Diagnostics and Epidemiology of Colorectal Cancer. Visceral Medicine. 2016;32(3):158-164.

43. Solomon S, Mulugeta W. Diagnosis and Risk Factors of Advantage Cancers in Ethiopia. Journal of cancer prevention. 2019;24(3):163-172.

44. Addis Ababa City Cancer Registry E. Addis Ababa City Cancer Registry Cancer incidence Report. African Cancer Registry Network, . 2019(Available from https://afcrn.org/membership/members/100-Addisababa).

45. Pan Y, Chieng C, Haris A, Ang S. Assessment of the level of knowledge of colorectal cancer among public at outpatient clinics in Serdang Hospital: a survey based study. The Medical journal of Malaysia. 2017;72(6):338-344.

46. Mhaidat NM, Al-husein BA, Alzoubi KH, et al. Knowledge and awareness of colorectal cancer early warning signs and risk factors among university students in Jordan. Journal of Cancer Education. 2018;33(2):448-456.

47. Imran M, Sayedalamin Z, Alsulami SS, Atta M, Baig M. Knowledge and awareness of colorectal cancer among undergraduate students at King Abdulaziz University, Jeddah, Saudi Arabia: a surveybased study. Asian Pac J Cancer Prev. 2016;17(5):2479-2483.

48. Alsayed MA, Surrati AM, Altaifi JA, Alharbi AH, Alfouti RO, Alremaithi SM. Public Awareness of Colon Cancer Symptoms, Risk Factor, and Screening at Madinah-KSA. International Journal of Pharmaceutical Research \& Allied Sciences. 2019;8(1).

49. Almalki WE, Alzhoufui HA, Altwaijry MA, Dad AM, Khoshhal OK. The Awareness of colorectal cancer and its risk factors in Madinah, Saudi Arabia: a cross-sectional study. 
50. Al-Sharif M, Fayi K, Alobaidi A, Alshamrani B. Awareness of colorectal cancer among public in Asir region. Journal of Family Medicine and Primary Care. 2018;7(1):87-92.

51. Power E, Simon A, Juszczyk D, Hiom S, Wardle J. Assessing awareness of colorectal cancer symptoms: measure development and results from a population survey in the UK. BMC cancer. 2011;11(1):366.

52. Bowles EJ, Yu O, Ziebell R, et al. Cardiovascular medication use and risks of colon cancer recurrences and additional cancer events: a cohort study. BMC cancer. 2019;19(1):270.

53. Hussain I, Majeed A, Rasool MF, et al. Knowledge, attitude, preventive practices and perceived barriers to screening about colorectal cancer among university students of newly merged district, Kpk, Pakistan-A cross-sectional study. Journal of Oncology Pharmacy Practice. 2020:1078155220922598.

54. Harun M, Che'Mat SH, Jalil AZA. Public expenditure expansion and inter-ethnic and ruralurban income disparity. Procedia Economics and Finance. 2012;1:296-303.

55. Selangor IusIC. Malaysian Communications and Multimedia Commission. http://wwwskmmgovmy/skmmgovmy/media/General/pdf/InternetUsers-Survey-2014pdf. 2015.

56. Elshami M, Elshami A, Alshorbassi N, et al. Knowledge level of cancer symptoms and risk factors in the Gaza Strip: a cross-sectional study. BMC Public Health. 2020;20(1):1-11.

57. Pătrășescu M, Nuță P, Costache RS, et al. Diabetes mellitus and colorectal cancer-a revealed connection. RJMM.13.

58. American Cancer Society, Colorectal Cancer: Risk Factors and Prevention. American Cancer Society 2018(Available from www.cancer.org/cancer/colon-rectalcancer/about/what-iscolorectal-cancer.html):21.

59. Su TT, Goh JY, Tan J, et al. Level of colorectal cancer awareness: a cross sectional exploratory study among multi-ethnic rural population in Malaysia. BMC Cancer. 2013;13(1):376.

60. Hamza A. Awareness of Colorectal Cancer and Associated Factors among Adult Patients Attending Jimma University Medical Center South-West Ethiopia, 2020 [dissertation]. Addis Ababa: http://etd.aau.edu.et/handle/123456789/21937. 


\section{Figures}

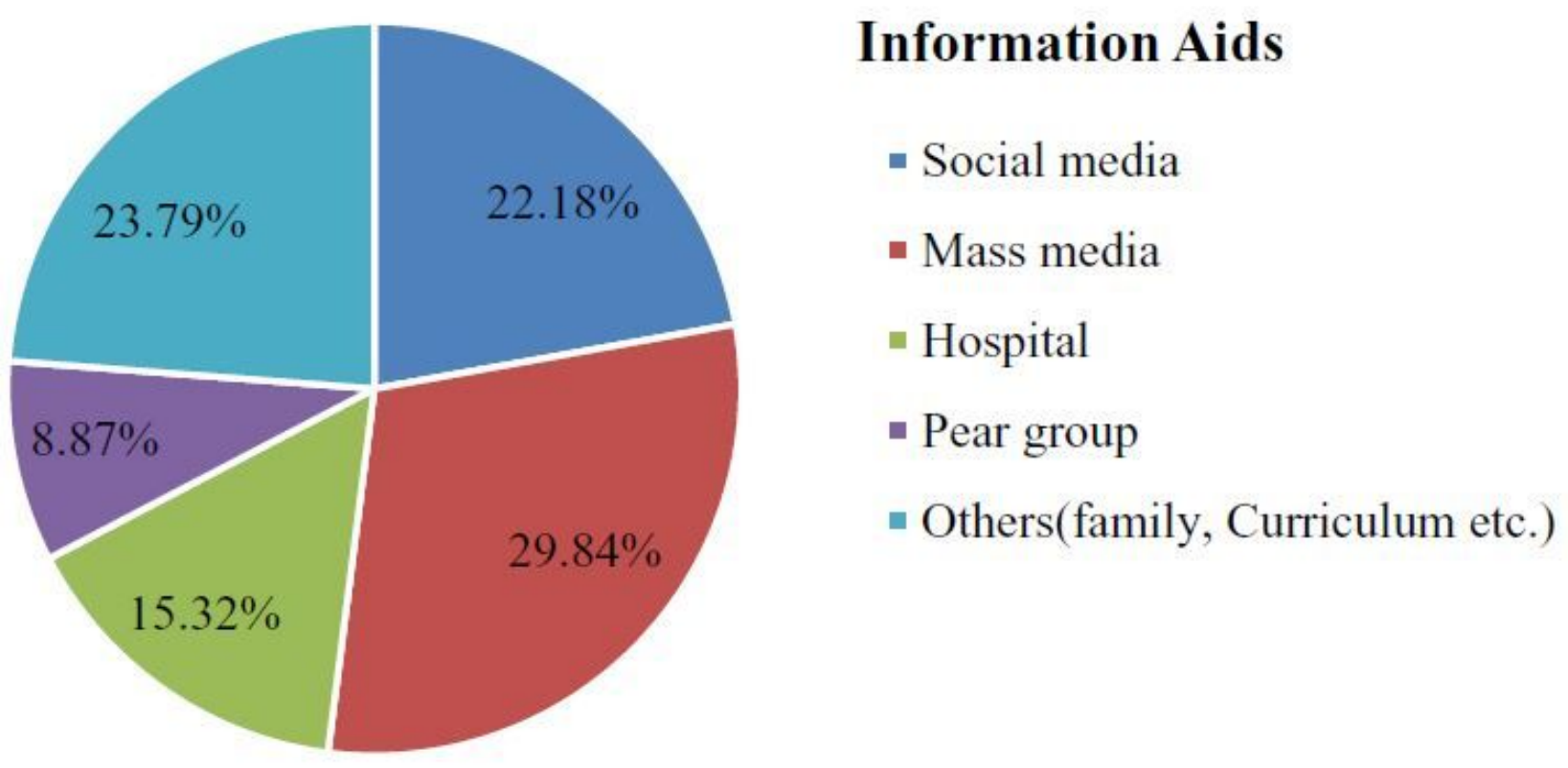

Figure 1

Sources of information about CRC among patients JUMC, Jimma, South-West Ethiopia, $2020(n=422)$. 


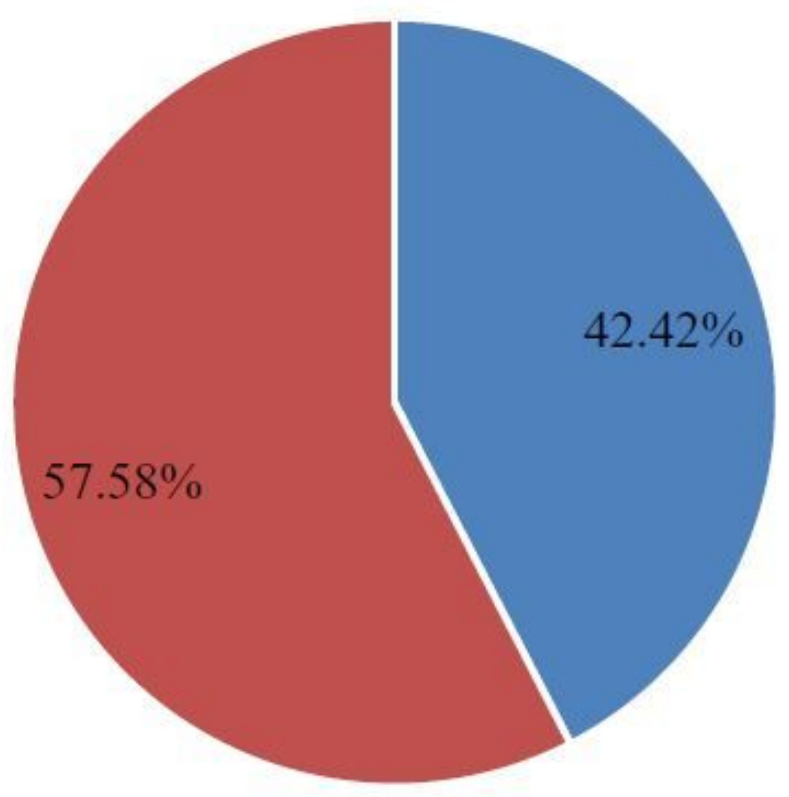

\section{Level of Awareness}

- High awareness

- Low awareness

\section{Figure 2}

Overall level of awareness of patients attending JUMC, Jimma, South-West Ethiopia, $2020(n=422)$.

\section{Supplementary Files}

This is a list of supplementary files associated with this preprint. Click to download.

- Table1.JPG 